\title{
Synaptic Interactions in Germinal Centers
}

\author{
Ilenia Papa and Carola G. Vinuesa* \\ John Curtin School of Medical Research, Australian National University, Acton, ACT, Australia
}

The germinal center (GC) is a complex, highly dynamic microanatomical niche that allows the generation of high-affinity antibody-producing plasma cells and memory B cells. These cells constitute the basis of long-lived highly protective antibody responses. For affinity maturation to occur, B cells undergo multiple rounds of proliferation and mutation of the genes that encode the immunoglobulin $V$ region followed by selection by specialized $T$ cells called follicular helper $T\left(T_{F H}\right)$ cells. In order to achieve this result, the $\mathrm{GC}$ requires spatially and temporally coordinated interactions between the different cell types, including B and T lymphocytes and follicular dendritic cells. Cognate interactions between $T_{F H}$ and GC B cells resemble cellular connections and synaptic communication within the nervous system, which allow signals to be transduced rapidly and effectively across the synaptic cleft. Such immunological synapses are particularly critical in the GC where the speed of T-B cell interactions is faster and their duration shorter than at

OPEN ACCESS

Edited by:

Shahram Salek-Ardakani,

Pfizer, United States

Reviewed by:

Jason G. Cyster,

University of California, San

Francisco, United States

Deepak Rao,

Harvard Medical School,

United States

*Correspondence:

Carola G. Vinuesa

carola.vinuesa@anu.edu.au

Specialty section:

This article was submitted to

T Cell Biology,

a section of the journal

Frontiers in Immunology

Received: 24 June 2018

Accepted: 27 July 2018

Published: 13 August 2018

Citation:

Papa I and Vinuesa CG (2018)

Synaptic Interactions in

Germinal Centers.

Front. Immunol. 9:1858.

doi: 10.3389/fimmu.2018.01858 other sites. In addition, the antigen-based specificity of cognate interactions in GCs is critical for affinity-based selection in which B cells compete for $T$ cell help so that rapid modulation of the signaling threshold determines the outcome of the interaction. In the context of GCs, which contain large numbers of cells in a highly compacted structure, focused delivery of signals across the interacting cells becomes particularly important. Promiscuous or bystander delivery of positive selection signals could potentially lead to the appearance of long-lived self-reactive B cell clones. Cytokines, cytotoxic granules, and more recently neurotransmitters have been shown to be transferred from $T_{F H}$ to B cells upon cognate interactions. This review describes the current knowledge on immunological synapses occurring during GC responses including the type of granules, their content, and function in $\mathrm{T}_{\mathrm{FH}}$-mediated help to B cells.

Keywords: $\mathbf{T}$ follicular helper $\left(\mathrm{T}_{\mathrm{FH}}\right)$ cell, germinal center, germinal centre $\mathrm{B}$ cells, immunological synapse, dense core granules

\section{IMMUNE SYNAPSE: PRINCIPLES, ORGANIZATION, AND STRUCTURE}

The term synapse was first used to describe the typical neural connections in the nervous system, which allow transmission of an electrical or chemical signal from one neuron to a responding cell in close physical contact. Immunologists then co-opted the term and referred to "immunological synapse" to describe the interactions between an antigen-presenting cell (APC) and an antigenreceptor expressing immune cell that involve close contact and the release of molecules such as cytokines across the synaptic space $(1,2)$.

When naive T cells recognize peptide-MHC on APCs via their TCRs, the TCRs become organized into structures of $\sim 500 \mathrm{~nm}$ known as microclusters (MCs). These MCs are more efficient in the 
recruitment of kinases and adapters that can initiate an activation signaling cascade (3). During formation of the immunological synapse, the TCR-MCs localize at the center of the interface between the $\mathrm{T}$ cells and the APC giving rise to the central supramolecular activation cluster (cSMAC) (4-7). This cSMAC is also called the bull's eye-type immunological synapse, due to its characteristic appearance, as first described by Kupfer (8). The immunological synapse between a $\mathrm{T}$ cell and an APC requires close juxtaposition of the membranes from the two different cell types. This is facilitated by a kinetic segregation of molecules that excludes negative regulatory phosphatases such as CD45 that relocates to the most external region or distal SMAC, and allows concentration of the key TCR signaling molecules at the center. This segregation process has been suggested to be an integral part of immune synapse function (9).

Besides TCR signaling, integrins play a key role in $\mathrm{T}$ cell activation facilitating the formation of conjugates between $\mathrm{T}$ cells and APCs. Lymphocyte function-associated antigen-1 (LFA-1) is one of the most important integrins during the process of T cell activation. LFA-1 and its high-affinity ligand intercellular adhesion molecule 1 (ICAM-1), localize outside of the cSMAC, at the peripheral SMAC (pSMAC). The inside-out signal from TCR or chemokine stimulation elicits conformational changes in LFA-1 that increase affinity for its ligands and therefore adhesion between the interacting cells (10). Binding of LFA-1 by ICAM1 , then leads to what is known as "outside-in" signaling, which contributes to many aspects of $\mathrm{T}$ cell activation.

Most membrane-proximal signaling molecules crucial for T cell activation such as ZAP70, LAT, SLP76, PLC- $\gamma$, etc., are recruited to TCR-MCs. Regulation of these large proteincomplexes determines the outcome of $\mathrm{T}$ cell activation, not just in terms of TCR signaling strength but also with regards to the nature of the resulting effector cells $(7,11)$. It is still unclear how different activation, differentiation, and survival outcomes can derive from changes in the signal strength downstream of these signaling complexes.

Together with T-cell antigen receptors and integrins, two additional groups of receptors are located at the synapse: adhesion and costimulatory receptors. Adhesion is mediated by heterophilic interactions between the signaling lymphocyte activation molecules (SLAM) family members CD2 (expressed on T cells) and CD58 (expressed on APCs). These CD2-CD58 interactions can contribute to TCR signaling processes even when direct TCR stimulation is absent (12).

It has been known for over two decades that costimulatory receptors are poor in eliciting activation signals or inducing cell adhesion on their own, but when combined with signals from other receptors, most prominently the TCR, they can potently enhance $\mathrm{T}$ cell activation, adhesion, and differentiation (13-15). The typical T cell costimulator is CD28, a member of the Ig superfamily characterized by a homodimeric structure and a cytoplasmic domain. The cytoplasmic domain of CD28 recruits and activates Lck, which can then phosphorylate and activates protein kinase $C$ (PKC)- $\theta$. In T cells PKC- $\theta$, a critical $\mathrm{PKC}$ isoform, contributes to the activation of NF- $\kappa \mathrm{B}$ transcription factors and promotes IL-2 production (16). Ligation of B7-1 (CD80) and B7-2 (CD86) on APCs and interaction within an immunological synapse regulate CD28 activity (17). Upregulation of CD80 and CD86 on DCs is a downstream effect of toll-like receptors signals and inflammatory cytokines $(18,19)$. In addition, expression of the inducible T cell costimulator, ICOS on activated T cells helps recruitment of the p50 $\alpha$ $\mathrm{PI} 3 \mathrm{~K}$ regulatory subunit to the immunological synapse, resulting in stronger activation of PI3K (20).

\section{B CELL-FOLLICULAR DENDRITIC CELL (FDC) SYNAPSES}

Synaptic interactions between B cells and FDCs are key for $B$ cells to efficiently extract antigen held in the form of immune complexes on FDCs, and to promote $\mathrm{B}$ cell survival until $\mathrm{T}_{\mathrm{FH}}$ selection and survival signals are delivered. Only those germinal center (GC) B cells able of binding and taking up antigen from FDCs to then present processed peptide to $\mathrm{T}_{\mathrm{FH}}$ cells can survive and differentiate into memory B cells or plasma cells. Immune complexes in association with activated complement components are bound by immunoglobulin receptors, CD35 and CD21 expressed on FDCs. Interaction between the BCR and antigen held in these immune complexes induces BCR signaling, BCRantigen $\mathrm{MC}$ formation followed by the formation of a mature immune synapse and antigen internalization for subsequent processing and presentation to T cells (21-23).

In vitro studies suggested that $\mathrm{GC} B$ cells form unique synaptic structures compared to other B cell subsets (24). GC $B$ cells form synapses containing less antigen than naive B cells, and the antigen is confined preferentially to the pSMAC rather than being localized at the cSMAC. In addition, some GC B cells form small synapses using their characteristic and previously described lamellipodia-like protrusions (24-26).

The early observation that B cells can acquire antigen that is bound to a surface suggested that mechanical forces are required for this process (21). Subsequently, it has been demonstrated that B cells are able to pull and internalize antigens (24), this process is dependent on the nature of the antigen nature and on the physical characteristics of antigen presentation (27). Stiff substrates, such as the FDC membrane, allow higher affinity discrimination, whereas antigen extraction from flexible substrates is more efficient. These findings, together with the observation that GC B cells require stronger forces in order to pull and take up antigen from the synaptic interface compared to naive B cells (24), support the importance of synaptic interactions between FDCs and GC B cells in affinity maturation and antibody production.

The synaptic interactions between GC B cells and FDCs involve several molecules (Figure 1). The first group comprises adhesion proteins such as B cell expressed LFA-1 that interacts with ICAM-1 on FDCs, and very-late activation antigen 4 (VLA-4) that interacts with VCAM-1 (28). These molecules do not deliver directly anti-apoptotic signals, but promote the anti-apoptotic functions of FDCs by augmenting cell-cell contact. Of note, GC $\mathrm{B}$ cells undergo apoptosis when separated from FDCs.

Expression of VCAM-1 and ICAM-1 on FDCs relies on NF-kB signaling (29) downstream of FC $\gamma$ RIIB, as Fcgr2b ${ }^{-/-}$mice 


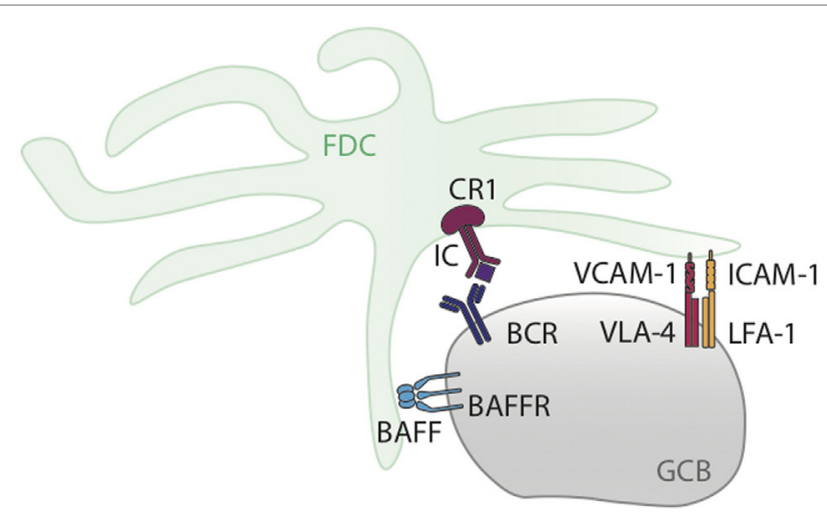

FIGURE 1 | Graphical representation of GC B cell-follicular dendritic cell (FDC) interaction in the germinal center (GC). The diagram shows key molecules involved in the interactions between GC B cells and FDCs happening during $\mathrm{GC}$ responses and discussed in Section "B Cell-Follicular Dendritic Cell (FDC) Synapses."

fail to upregulate Icam1 or Vcam1 mRNA and protein on FDCs after immunocomplex formation (30). In mice lacking NF- $\kappa B$ signaling in FDCs, GCs were smaller and contained more apoptotic cells. Also primary responses to sheep red blood cells were partially reduced and secondary immunizations did not induce strong responses (29), although this could be due to other processes rather then a direct effect of ICAM-1/VCAM-1 regulation.

In vitro studies have suggested that the integrins ICAM-1 and VCAM-1 may play a role in GC B cell survival. Indeed, Lindhout et al. showed that direct interaction between FDCs and human GC B cells facilitated GC B cell survival in culture (31). Subsequent studies revealed that equivalent survival could be achieved when replacing FDCs by coating VCAM-1 and ICAM-1 to the culture plates (28). Rapid death of GC B cells has been shown after diphtheria toxin-mediated ablation of FDCs in vivo, supporting a role of FDCs in promoting GC B cell viability (32). It has also been shown in vivo that mutation in DOCK8, member of a family of proteins critical for the activation of the Rho family of small GTPases, lead to disrupted concentration of ICAM-1 on $B$ cells forming immune synapses, affecting their survival and affinity maturation (33). Nevertheless, a separate study showed minimal impact of ICAM1 and VCAM1 loss from FDCs on the magnitude of the GC response in vivo (34), which questions the importance of FDC-expressed VCAM1 and ICAM1 in GC $\mathrm{B}$ cell survival. It is possible that these interactions play a more significant role under some immunization conditions and may differentially impact the plasma cell or memory B cell response.

The second group of molecules influencing FDC-GC B cell interactions comprises pro-survival molecules and growth factors. The B cell survival factor BAFF-also known as BLys-is produced at high amounts by activated FDCs. Despite its well-described role in the survival of peripheral B cells, it is still unclear whether BAFF plays a role in GC B cell survival. In vivo studies describing GC formation with relatively preserved affinity maturation in BAFF-deficient mice suggest it is dispensable (35-37). BAFF/BAFF-R signaling does, however, appear to have a function in GC maintenance, as in the absence of this factor,
GCs disappear a few days after their formation. Lack of BAFF also leads to failure of FDC maturation and as a consequence, stimulation of B cells through immune complexes cannot occur $(35,37)$. It is plausible this FDC phenotype may be an indirect effect of B cell lymphopenia in the absence of BAFF. In BAFF-R defective $\mathrm{A} / \mathrm{WySnJ}$ mice, the FDC reticulum was normal and GCs could form, but proliferation of GC B cells was impaired (35). BAFF also signals through the receptors TACI and BCMA and mice deficient in these receptors displayed normal GC formation $(38,39)$ suggesting BAFF-R signaling is responsible for the observed effects of BAFF on GC B cells. However, some B cells in $\mathrm{A} / \mathrm{WySnI}$ mice (lacking BAFF-R) are able to mature, enter the $\mathrm{GC}$ reaction and support FDC maturation, whereas $\mathrm{B}$ cells from BAFF-deficient mice cannot (40), suggesting that in the absence of BAFF-R, the other receptors for BAFF and/or APRIL (BCMA or TACI) may take over the B cell maturation function of BAFF-R, although they do not play an essential role in GC maintenance.

Besides the production of survival factors, FDCs are known for their expression of transmembrane molecules such as the transcobalamin receptor 8D6, and cytokines including IL-6 and IL-15 $(41,42)$. These surface-expressed or secreted products can also participate in the growth of GC B-cells. 8D6, also known as or CD320 can promote GC B cell growth. 8D6 also appears to support the proliferation of plasma cell precursors generated by IL-10, enhancing antibody secretion $(42,43)$. Human FDCs also produce IL-15, and in vitro its membrane-bound form has been shown to signal through IL-2/IL-15R $\beta(44,45)$ to enhance proliferation of GC B cells. This proliferative effect has not been observed for IL-6, although this cytokine is required for proper GC formation (46). It is possible, however, that the effect of IL-6 on GC B cells is indirect, through its well-demonstrated role in promoting $\mathrm{T}_{\mathrm{FH}}$ cell induction and maintenance $(47,48)$.

Besides their effects on GC B cells, FDCs also regulate $\mathrm{T}_{\mathrm{FH}}$ cells. FDC-derived IL- 6 has also been suggested to be important for $\mathrm{T}_{\mathrm{FH}}$ cell maintenance (47). Interactions between $\mathrm{T}_{\mathrm{FH}}$-expressed TIGIT $(49,50)$ and its receptor on FDCs-the high-affinity poliovirus receptor (CD155) $(49,50)$ may also contribute to $\mathrm{T}_{\mathrm{FH}}$ regulation by FDCs during thymus-dependent (TD) B cell responses. $\mathrm{CT}_{\mathrm{FH}} \mathrm{TIGIT}^{+}$cells have been shown to exhibit strong $\mathrm{B}$ cell helper functions, inducing plasma cell differentiation and immunoglobulin production (51). Engagement of TIGIT by CD155 promotes IL-10 while it restrains IL-12 production by DCs, leading to reduced $\mathrm{T}$ cell activation in vitro (52).

\section{$T_{\text {FH-GC B SYNAPSES }}$}

Synaptic interactions between $\mathrm{T}_{\mathrm{FH}}$ and GC B cells are essential for GC formation and GC B cell selection as they facilitate the delivery of T cell-derived helper molecules. Formation of optimal $\mathrm{T}_{\mathrm{FH}}-\mathrm{GC} \mathrm{B}$ cell synapses depends on specific interactions between the receptor:ligand pairs described below and summarized in Figure 2 .

\section{ICAM-1:LFA-1}

Intercellular adhesion molecule 1 also known as cluster of differentiation 54 is a ligand for the integrin LFA- 1 and this pair forms 

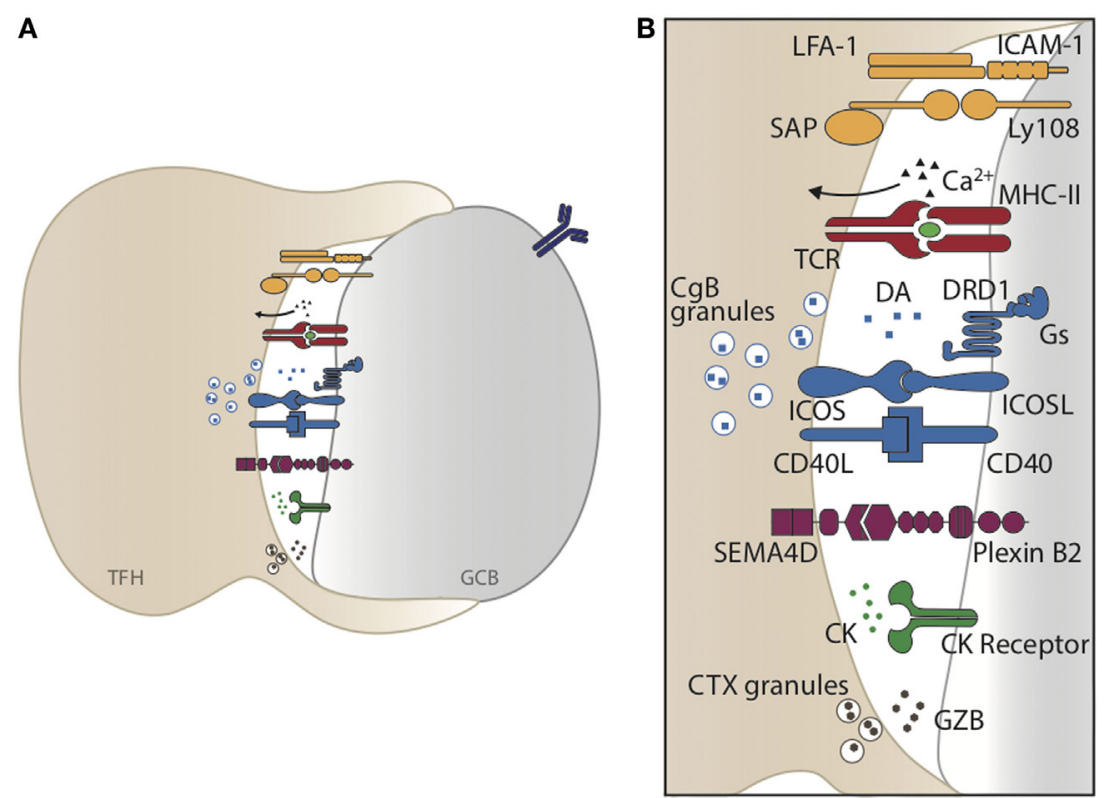

FIGURE 2 | $T_{F H}$-germinal center (GC) B cell synaptic interaction. (A) Graphical representation of $T_{F H}$ and GC B cell interaction. Formation of optimal $T_{F H}-G C$ B cell synapses depends on specific interactions between receptor:ligand pairs and integrins, leading to a specific and focused transmission of cytokines, neurotransmitters, and cytotoxic granules. (B) Enlarged representation of the synaptic cleft forming upon $\mathrm{T}_{\mathrm{FH}}-\mathrm{GC}$ B cell interaction.

the peripheral ring (pSMAC) of immune synapses. As mentioned above, during T cell-APC synapses, TCR activation upon binding peptide-MHC II molecules leads to a conformational change in LFA-1 and clustering of LFA-molecules. These structural and positional changes are critical to increase the affinity for ICAM molecules via the formation of multivalent associations (53). LFA-1 binding to ICAMs was also shown to be critical for adequate $\mathrm{T}$ cell activation and differentiation into effector cells $(54,55)$.

$\mathrm{T}_{\mathrm{FH}}$ cells express high levels of LFA-1 (56) and Ag-specific B cells express higher levels of ICAM-1 compared to non Ag-specific cells (57). In addition to cognate pMHCII:TCR interactions, adhesive mechanisms and costimulatory receptors are critical for facilitating T-B conjugate formation and optimal TCR activation $(54,55,58)$. Recently Zaretsky and colleagues showed that expression of two LFA-1 ligands on B cells-ICAM-1 and ICAM-2-was required to form the stable and lasting antigendriven $\mathrm{T}_{\mathrm{FH}}-\mathrm{GC} \mathrm{B}$ cell interactions that promote $\mathrm{B}$ cell selection. Thus, the $\mathrm{B}$ cell antibody response to protein antigens depends on B cell ICAMs for optimal selection by $\mathrm{T}_{\mathrm{FH}}$ cells. High levels of antigen can sustain short T-B interactions, however, optimal long-lasting contacts are strictly ICAM-dependent (57).

\section{CELL SURFACE-POLARIZED STIMULATORY MOLECULES}

\section{CD40:CD40L}

$\mathrm{T}_{\mathrm{FH}}-\mathrm{GC} \mathrm{B}$ cell contacts require interactions between several key molecules. Among those, CD40L:CD40 interactions play crucial roles within GCs. Consequences of defective CD40-CD40L signaling highlight their important role in initiation and maintenance of GC responses. Blocking CD40 signals in established GCs leads to complete and rapid GC dissolution in mice (59). Indeed CD40 is critical for GC maintenance and enables light zone (LZ) cells to recycle back to the dark zone and sustain the GC response. In humans, CD40 deficiency causes hyper-IgM syndrome characterized by lack of switched memory B cells and switched serum immunoglobulins. CD40L was also shown to provide survival signals to human GC B cells (60). In mice, CD40 signals also induce ICOSL expression on GC B cells (61).

CD40L is found preformed in GC T cells (62) and is rapidly and transiently relocated on the T cell surface upon TCR ligation. There is recent evidence in mice that ICOS signals can contribute to $\mathrm{CD} 40 \mathrm{~L}$ upregulation. Indeed, as described above ICOSL signals delivered by GC B cells support the transient but extensive "entanglement" with $\mathrm{T}_{\mathrm{FH}}$ cells, which in turn stimulates the increased expression of CD40L on the surface of $\mathrm{T}_{\mathrm{FH}}$ cells (61). CD40L-mediated upregulation of ICOSL expression by GC B cells, followed by ICOSL induction of further CD40L expression on $\mathrm{T}_{\mathrm{FH}}$ cells has been described as a feed-forward loop that enables high-affinity B cells to repeatedly acquire more T cell help than their lower affinity competitors (61).

Outside GCs it has been shown that both Th1 and Th2 cells transfer CD40L to B cells in an antigen-specific manner (63). Although cultured Th1 and Th2 cells have distinctive immunological synapse structures (64) with Th1 displaying a classical immune synapse and Th2 a multifocal synapse structure, both cell types are equally efficient in antigen-specific T-B interaction (63). Future analysis will be required to confirm the immunological synapse organization of primary Th1 and Th2 cells. In human primary $\mathrm{T}_{\mathrm{FH}}$ cells, CD40L accumulated in the cSMAC 
on supported lipid bilayers containing CD40 and ICOSL (65), suggesting that $\mathrm{T}_{\mathrm{FH}}-\mathrm{GC} \mathrm{B}$ cell synapses display the structure of a classical immunological synapse.

\section{SLAM Family Members and SLAM- Associated Protein (SAP)}

SLAM-associated protein expression in $\mathrm{T}$ cells has been shown to be important for adhesive cognate T-B cell interactions. In the absence of SAP, T-B interactions were less stable and were not long-lasting, impairing $\mathrm{T}_{\mathrm{FH}}$ differentiation. This stabilization was shown to be a consequence of T-cell intrinsic signaling of SAP, which serves as an adaptor for the SLAM family of immune receptors at the cell-cell interface. B cells express high levels of several SLAM family members including SLAM, CD84, Ly9, and Ly108 molecules. These same molecules are also found in substantial amounts on the surface of activated $\mathrm{T}$ cells and in $\mathrm{T}_{\mathrm{FH}}$ cells (66-70). Most SLAM family members bind in a homophilic fashion to the same molecule expressed on the interacting cell. SLAM molecules recruit SAP to their cytoplasmic tail leading to the downstream signaling cascade required to induce stable adhesive interactions $(67,71)$. In vitro experiments have proposed that CD84 and Ly108 act together during $\mathrm{T}-\mathrm{B}$ cell synaptic interactions to promote the $\mathrm{T}_{\mathrm{FH}}$ cell phenotype (66). SAP act as a break to Ly108-mediated recruitment of the inhibitory phosphatase SHP-1 to the T cell synapse. SHP-1 dephosphorylates immunotyrosine switch motifs normally bound by SAP, to limit T-B cell adhesion and prevent formation of sustained T-B cell synaptic interactions. The need of stable T-B cell interactions for an efficient GC response and production of disease-inducing autoantibodies has been also described in the context of autoimmunity (72). It is important to note that the role of SAP/SLAM in stabilizing cognate interactions between $\mathrm{T}$ cells and APCs appears to be essential in achieving sustained cognate $\mathrm{T}-\mathrm{B}$ interactions, but not for T:DC interactions, which are more dependent on integrins (66).

$\mathrm{T}$ cell costimulatory ligands expressed by $\mathrm{B}$ cells also play key roles in $\mathrm{T}-\mathrm{B}$ interactions and the resulting proliferation and differentiation of both T and B cells. CD80 and CD86 are markers of $\mathrm{B}$ cell activation and function providing important costimulatory signals via CD28 that promote $\mathrm{T}$ cell proliferation and cytokine production. CD86 is expressed by LZ B cells and promotes the APC capability of B cells (73). Reducing the availability of CD86 molecule by the injection of a blocking antibody (GL-1) during primary responses to NP-CGG resulted in the reduction of serum Ab titers, either IgM or IgG (59) whereas IL-21-mediated sustained elevation of CD86 augmented the magnitude of $\mathrm{CD} 4 \mathrm{~T}$ cell responses both in vitro and in vivo (74). CTLA-4, which is found at high amounts on regulatory cells and some follicular $\mathrm{T}$ cells, can also bind to and transendocytose CD86 (75) but its function in GC reactions is still not clear.

\section{Plexin B2 (PIxnB2), Ephrin B1, and BASP1}

Plexins constitute a family of transmembrane receptors for semaphorins and regulate multiple processes including synapse formation and axon guidance in the nervous system (76).
PlxnB2 is expressed in the central nervous system upon binding semaphorins promotes axon guidance and migration (77). In the immune system, GC B cells formed in the context of TD but not thymus-independent responses express high amounts of PlxnB2 $(25,26)$. Recent studies have revealed that PlxnB2 expressed by GC B cells is sensed by Semaphorin 4C (Sema4C) expressed on $\mathrm{T}_{\mathrm{FH}}$ cells. This PlxnB2-Sema4C interaction promotes $\mathrm{T}-\mathrm{B}$ adhesion in an antigen-independent manner and guides $\mathrm{T}_{\mathrm{FH}}$ cell recruitment to the GC (78). For this, PlxnB2 expressed on GC B cells promotes $T_{F H}$ migration from the $\mathrm{T}$ zone to the border of the GC. Once positioned at the GC edge, $\mathrm{T}_{\mathrm{FH}}$ cells have easier access into the GC. The evidence that this positioning is the critical first step comes from the observation that in mice lacking B cell expressed PlxnB2, $\mathrm{T}_{\mathrm{FH}}$ cells accumulate at the edge of the GC. In these mice, GC T-B interactions are diminished resulting in poor GC-derived antibody responses, including the production of high-affinity antibodies and long-lived plasma cells (78).

In the GC, members of the Ephrin receptors family and their ligands also regulate cell migration and cell-to-cell interaction. Ephrin type-B receptor 4 (EPHB4) and EPHB6 are expressed on $\mathrm{T}_{\mathrm{FH}}$ cells (79) and one of their ligands, Ephrin-B1 (EFNB1) has been found on GC B cells $(79,80)$. Ephrin ligands and their receptors are membrane-bound proteins that require direct cell-cell interaction to bind and activate downstream signaling pathways. EFNB1 suppresses GC B- $\mathrm{T}_{\mathrm{FH}}$ cell adhesion, and mice lacking its expression showed reduction in plasma cell production and accumulation of IL-21_deficient T follicular helper cells within the GC (79). Intriguingly, EPNB1 has been reported to be expressed in a subset of GC B cells that share phenotypic features with memory B cells and are preferentially located in the LZ and outer areas of GCs. It is therefore possible that Ephrin interactions also regulate $\mathrm{T}_{\mathrm{FH}}-\mathrm{B}$ cell interactions leading to memory B cell formation from GC B cells (80).

BASP1 is a myristoylated protein highly expressed in the brain and localized at the inner surface of the plasma membrane in presynaptic neurons. In planar lipid bilayers BASP1 can exert ion channel activity (81). In neurons, BASP1 mediates neurite outgrowth and axonal repair (82). BASP1 expression is absent on resting murine splenic B cells, but can be induced by B-cell activation with anti-IgM and anti-CD40 and is again selectively and strongly upregulated in TD GC B cells. BASP1 is therefore likely to control synaptic processes in GC B cells.

\section{TRANSMITTED MOLECULES}

\section{Delivery of Cytokines Across Immune Synapses}

One of the major roles of both neurological and immunological synapses is the focused secretion of soluble components into the synaptic cleft where the secreted factors can achieve the desired concentration and selectively act on the precise postsynaptic neuron or antigen-specific lymphoid cell (83-85).

There is also increasing evidence of transfer of cellular contents from T cells to APCs in the form of microvesicles. This is a highly dynamic process by which microvesicles formed 
within the $\mathrm{T}$ cell are then released into the synaptic interface and taken up by APCs. Within APCs, the contents of microvesicles, which include proteins, RNAs, and microRNAs, can influence gene expression and activation of early signaling pathways $(86,87)$. Transfer in the opposite direction also occurs at the synaptic cleft: indeed, the process of trogocytosis, by which T cells can extract MHC:peptide complexes from APCs during endocytosis of engaged TCRs, has been shown to be important for sustained signaling at endosomes $(88,89)$. Together, these findings suggest that immune synapses are key facilitators of transcellular communication.

$\mathrm{T}_{\mathrm{FH}}$-derived cytokines can be secreted and signal to B cells in a contact-independent manner. However, it seems that cell-cell contact can potently enhance the response. Indeed, secretion of cytokines across an immunological synapse can be highly effective due to the much higher concentrations that can be achieved within the synaptic space (90) are much more specific, because it is directed toward a B cell presenting cognate antigen. Variation in the amount of antigen presented can be detected in a highly sensitive manner, and the synapse can quickly change orientation to contact the cell presenting peptide:MHC complexes at the highest density. Together, these properties by which helper molecules get transmitted across an immune synapse are thought to enable $\mathrm{T}_{\mathrm{FH}}$ cells to select those $\mathrm{B}$ cells expressing BCRs with the highest affinity for the immunizing antigen.

The observation made by Reinhardt and colleagues offers an example of this effective cytokine delivery. The isolation of $\mathrm{T}-\mathrm{B}$ cell conjugates from the draining lymph node of immunized mice demonstrated that IgG1-producing B cells made contact with IL-4-producing $\mathrm{T}$ cells whereas IgG2a-producing B cells made contact with IFN- $\gamma$-producing T cells (91). IL-4-producing $\mathrm{T}$ cells were found conjugated to GC B cells expressing high levels of AID, with evidence of somatic hypermutation (91) demonstrating that $\mathrm{T}_{\mathrm{FH}^{-}}$-derived cytokines directly stimulate the production of different antibody isotypes in responding B cells sharing the same microenvironment. However, additional studies would be required to confirm these observations, perhaps using the LIPSTIC method, which allows direct measurement of dynamic cell-cell interactions both in vitro and in vivo (92).

\section{Neurotransmitters in T-B Synapses}

Neurotransmitters (NTs) are proteins used by the nervous system to communicate between neurons or other cells. This response typically occurs in response to changes in action potential when the neuron is activated. Substances acting as transmitters are stored in vesicles at synapses and are released by a process of exocytosis. Exocytosis in neurons occurs when depolarization of the neuron cell wall causes flux of calcium, binding of vesicles, and eventual externalization of vesicular content. Substances considered to be neurotransmitters are released into the synaptic cleft by exocytosis and/or directly from the cytoplasm. A neurotransmitter can be defined as a substance that is released by a neuron and that affects a specific target in a specific manner. A target can be either another neuron or an effector organ, such as muscle or gland. The concept of a transmitter is not precise, as neurotransmitters are protean, structurally resembling other released agents in many regards. NTs act on targets that are close to the site of transmitter release, in distinction to hormones that are released in the bloodstream to act on distant targets (93). The interaction of neurotransmitters with receptors is typically transient, lasting from milliseconds to minutes. Despite the short timeframe of interaction, neurotransmitter action can result in long-term changes within target cells lasting hours or days.

Dopamine (DA) is a catecholamine mainly synthetized in the central nervous system where it acts as a neurotransmitter. The rate-limiting step in catecholamine synthesis is the conversion of tyrosine into L-DOPA by the enzyme tyrosine hydroxylase. Dopamine is then synthetized from L-DOPA by the enzyme DOPA decarboxylase. In the presence of other enzymes, dopamine can be further converted into noradrenaline and adrenaline.

In neurons, dopamine is packaged into vesicles after synthesis and can be released into the synaptic cleft upon the occurrence of a presynaptic action potential. Neuronal cells can also secrete dopamine into peripheral tissues. Furthermore, dopamine can also be synthetized within specific parenchymal tissue and endothelial cells $(94,95)$. Nevertheless, despite evidence of endothelial and other sources of peripheral dopamine production, the main contributor to plasma dopamine levels is production by sympathetic nerves.

An emerging role for dopamine in the immune system has recently been recognized. Dopamine can be produced by immune cells such as $\mathrm{T}$ cells and dendritic cells, and its release has various autocrine and paracrine effects (96-107).

Only recently, a role for dopamine in the GC reaction has been described (65). High dopamine amounts are found in $\mathrm{T}_{\mathrm{FH}}$ cells compared to other $\mathrm{T}$ cell subsets analyzed. Dopamine is typically stored in dense core granules. Chromogranin B $(\mathrm{CgB})$ is a marker of dense core secretory granules in the neuroendocrine system and is involved in the packaging of catecholamines, such as dopamine and noradrenaline. $\mathrm{CgB}^{+}$ granules are found in a small percentage of human $\mathrm{T}_{\mathrm{FH}}$ cells. $\mathrm{T}_{\mathrm{FH}}$ cells can synthetize dopamine upon cAMP induction and release it during T-B cell synapse formation. Once released, dopamine can bind to dopamine receptors expressed by human GC B cells and induce ICOSL translocation to the cell surface within minutes of stimulation. This effect appears to be mediated by dopamine receptor 1 (DRD1). Ligation of ICOS on human $\mathrm{T}_{\mathrm{FH}}$ cells leads to fast translocation of CD40L to the center of the synapse. Furthermore, ICOS ligation also augmented the area of the $\mathrm{T}_{\mathrm{FH}}-\mathrm{GC} \mathrm{B}$ cell synapse (65). This work adds to the growing evidence of the importance of ICOSL-mediated regulation of $\mathrm{T}$ cell help to GC B cells, required for productive GC reactions.

\section{Cytotoxic Granules and Granzymes}

Cytolytic granules are specialized secretory lysosomes containing a set of proteins, such as perforin and granzymes, involved in cell-mediated apoptosis $(108,109)$. Cytolytic granules can also be delivered through the immunological synapse. Specifically, this occurs through a secretory zone localized in the center of the synapse (110). Although cytotoxicity is a typical property of $\mathrm{CD}^{+} \mathrm{T}$ cells and natural killer cells, MHC class-II-restricted 
cytotoxicity mediated by $\mathrm{CD} 4^{+} \mathrm{T}$ cells has also been described in both humans and mice (111-116). CD4 ${ }^{+}$CTL have been identified mostly during viral infections, suggesting that one of the main roles of $\mathrm{CD} 4^{+}$CTLs is antiviral immunity. CD $4^{+}$CTLs have also been identified during antitumor responses $(117,118)$ and chronic inflammatory responses (119-121).

Recent findings in mice described that the infecting or immunizing virus influences $\mathrm{CD} 4{ }^{+} \mathrm{CTL}$ differentiation and that this differentiation program, once initiated, directly antagonizes $\mathrm{T}_{\mathrm{FH}}$ differentiation. CD4 CTLs express high levels of Blimp1 and low levels of Bcl6, which is required for $\mathrm{T}_{\mathrm{FH}}$ cell differentiation. Unlike the dependency of $\mathrm{T}_{\mathrm{FH}}$ cells on BCL6 and TCF1, these transcription factors prevent $\mathrm{CD} 4^{+} \mathrm{CTL}$ induction, suggesting a dichotomous differentiation pathway between $\mathrm{CD} 4^{+} \mathrm{T}_{\mathrm{FH}}$ and CTLs (122).

In human GCs a subset of $\mathrm{T}_{\mathrm{FH}}$ cells expressing the surface marker CD57 (HNK-1/Leu-7) show cytotoxic activity (123). CD57 is generally upregulated in cells with cytotoxic activity (124). Further characterization of the nature and function of these granules will be required.

\section{CONSEQUENCES OF T-B SYNAPTIC INTERACTIONS}

In the nervous system, calcium fluxes are essential facilitators of synaptic neurotransmission. Action potentials open calcium channels in the presynaptic membrane causing the uptake of calcium ions $\left(\mathrm{Ca}^{2+}\right)$. This calcium flux triggers the release of neurotransmitters from synaptic vesicles into the synaptic cleft. Calcium fluxes have been well studied in the context of T cell-APC synapse formation. It is only recently that calcium mobilization has been observed in the context of $\mathrm{T}_{\mathrm{FH}^{-}} \mathrm{GC} \mathrm{B}$ cell engagement.

Selection of high-affinity antibody-producing $\mathrm{B}$ cells is mediated by large but transient interactions between $T_{\mathrm{FH}}$ and GC B cells. It has been shown that in the presence of antigen, $\mathrm{T}$ cells reduce their speed and increase the duration and area of contact with high-affinity GC B cells. These interactions lead to an increase in $\mathrm{T}_{\mathrm{FH}}$ intracellular calcium, which in turn increases the amount of helper cytokines IL-4 and IL-21 (125). Subsequent studies showed that mouse GC T cells help B cells in GCs via formation of entangled contacts, require extensive $\mathrm{T}$ and $\mathrm{B}$ cell surface interactions and rapid CD40L translocation to the surface

\section{REFERENCES}

1. Grakoui A, Bromley SK, Sumen C, Davis MM, Shaw AS, Allen PM, et al. The immunological synapse: a molecular machine controlling $\mathrm{T}$ cell activation. Science (1999) 285:221-7. doi:10.1126/science.285.5425.221

2. Paul WE, Seder RA. Lymphocyte responses and cytokines. Cell (1994) 76:241-51. doi:10.1016/0092-8674(94)90332-8

3. Dustin ML. The immunological synapse. Cancer Immunol Res (2014) 2:1023-33. doi:10.1158/2326-6066.CIR-14-0161

4. Bunnell SC, Hong DI, Kardon JR, Yamazaki T, McGlade CJ, Barr VA, et al. $\mathrm{T}$ cell receptor ligation induces the formation of dynamically regulated signaling assemblies. J Cell Biol (2002) 158:1263-75. doi:10.1083/jcb. 200203043

5. Campi G, Varma R, Dustin ML. Actin and agonist MHC-peptide complexdependent $\mathrm{T}$ cell receptor microclusters as scaffolds for signaling. J Exp Med (2005) 202:1031-6. doi:10.1084/jem.20051182 of $\mathrm{T}_{\mathrm{FH}}$ cells. This translocation of preformed $\mathrm{CD} 40 \mathrm{~L}$ requires ICOS costimulation and calcium signaling (61). When ICOSL knockout $\mathrm{B}$ cells were engaged in interactions with $\mathrm{T}_{\mathrm{FH}}$ cells, smaller calcium fluxes in the $\mathrm{T}$ cells were detected.

$\mathrm{Ca}^{2+}$ mobilization is also important in B cells after BCR engagement leading to different outcomes depending on the presence of additional signals. BCR engagement alone by antigen triggers a $\mathrm{Ca}^{2+}$ flux that causes downregulation of constitutive ICOSL surface expression on activated B cells $(126,127)$ and in vitro stimulated GC B cells (65). This downregulation is potentiated when BCRs are engaged together with IL4R activation, which acts through STAT6 to cause complete loss of ICOSL surface expression. By contrast, costimulation of B cells through CD40 signals (but not LPS or cytokines) after downregulation by antigen and/ or IL-4 could restore expression of ICOSL. Restoration of ICOSL expression did not occur in B cells treated with anti-IgM. This was thought to be a consequence of high BCR crosslinking, since HEL stimulation, which does not crosslink BCRs, did not prevent ICOSL re-expression. Together these findings highlight that CD40-CD40L signaling and the nature of the antigen, control whether antigen-activated B cells are able to re-express ICOSL, which in turns leads to costimulation of the cognate T cell (126).

\section{CONCLUDING REMARKS}

The last decades of research in T-B cell interactions have revealed the importance of selective and focused delivery of important signals through the immunological synapse. Synaptic transmission of cytokines and neurotransmitters enables rapid regulation and translocation of molecules to the synaptic interface, required for effective $\mathrm{T}_{\mathrm{FH}}$-mediated $\mathrm{B}$ cell selection. Several molecules are known to be involved in the initiation of T-B immune synaptic transmission in GCs. Less is known about the signals required for the termination of $\mathrm{T}-\mathrm{B}$ cell interactions, or about signals that distinguish $\mathrm{T}_{\mathrm{FH}}-\mathrm{B}$ vs $\mathrm{T}_{\mathrm{FR}}-\mathrm{B}$ cell interactions. We expect the coming years will uncover a much larger array of neurotransmitterlike molecules involved in T-B interactions in GCs.

\section{AUTHOR CONTRIBUTIONS}

IP and CV conceived, designed, and wrote the manuscript. CV revised the manuscript.

6. Hashimoto-Tane A, Yokosuka T, Sakata-Sogawa K, Sakuma M, Ishihara C, Tokunaga $\mathrm{M}$, et al. Dynein-driven transport of $\mathrm{T}$ cell receptor microclusters regulates immune synapse formation and T cell activation. Immunity (2011) 34:919-31. doi:10.1016/j.immuni.2011.05.012

7. Yokosuka T, Sakata-Sogawa K, Kobayashi W, Hiroshima M, HashimotoTane A, Tokunaga $\mathrm{M}$, et al. Newly generated $\mathrm{T}$ cell receptor microclusters initiate and sustain T cell activation by recruitment of Zap70 and SLP-76. Nat Immunol (2005) 6:1253-62. doi:10.1038/ni1272

8. Monks CR, Freiberg BA, Kupfer H, Sciaky N, Kupfer A. Three-dimensional segregation of supramolecular activation clusters in T cells. Nature (1998) 395:82-6. doi:10.1038/25764

9. Davis SJ, van der Merwe PA. The kinetic-segregation model: TCR triggering and beyond. Nat Immunol (2006) 7:803-9. doi:10.1038/ni1369

10. Dustin ML, Bromley SK, Kan Z, Peterson DA, Unanue ER. Antigen receptor engagement delivers a stop signal to migrating T lymphocytes. Proc Nat Acad Sci U S A (1997) 94:3909-13. doi:10.1073/pnas.94.8.3909 
11. Cemerski S, Das J, Locasale J, Arnold P, Giurisato E, Markiewicz MA, et al. The stimulatory potency of $\mathrm{T}$ cell antigens is influenced by the formation of the immunological synapse. Immunity (2007) 26:345-55. doi:10.1016/j. immuni.2007.01.013

12. Kaizuka Y, Douglass AD, Vardhana S, Dustin ML, Vale RD. The coreceptor $\mathrm{CD} 2$ uses plasma membrane microdomains to transduce signals in $\mathrm{T}$ cells. J Cell Biol (2009) 185:521-34. doi:10.1083/jcb.200809136

13. Bromley SK, Iaboni A, Davis SJ, Whitty A, Green JM, Shaw AS, et al. The immunological synapse and CD28-CD80 interactions. Nat Immunol (2001) 2:1159-66. doi:10.1038/ni737

14. Lafferty KJ, Cunningham AJ. A new analysis of allogeneic interactions. Aust J Exp Biol Med Sci (1975) 53:27-42. doi:10.1038/icb.1975.3

15. Martin PJ, Ledbetter JA, Morishita Y, June CH, Beatty PG, Hansen JA. A 44 kilodalton cell surface homodimer regulates interleukin 2 production by activated human T lymphocytes. J Immunol (1986) 136:3282-7.

16. Kong KF, Yokosuka T, Canonigo-Balancio AJ, Isakov N, Saito T, Altman A. A motif in the V3 domain of the kinase PKC-theta determines its localization in the immunological synapse and functions in $\mathrm{T}$ cells via association with CD28. Nat Immunol (2011) 12:1105-12. doi:10.1038/ni.2120

17. Tseng SY, Waite JC, Liu M, Vardhana S, Dustin ML. T cell-dendritic cell immunological synapses contain TCR-dependent CD28-CD80 clusters that recruit protein kinase C theta. J Immunol (2008) 181:4852-63. doi:10.4049/ jimmunol.181.7.4852

18. Inaba K, Witmer-Pack M, Inaba $M$, Hathcock KS, Sakuta H, Azuma M, et al. The tissue distribution of the B7-2 costimulator in mice: abundant expression on dendritic cells in situ and during maturation in vitro. J Exp Med (1994) 180:1849-60. doi:10.1084/jem.180.5.1849

19. Medzhitov R, Preston-Hurlburt P, Janeway CA Jr. A human homologue of the Drosophila Toll protein signals activation of adaptive immunity. Nature (1997) 388:394-7. doi:10.1038/41131

20. Fos C, Salles A, Lang V, Carrette F, Audebert S, Pastor S, et al. ICOS ligation recruits the p50alpha PI3K regulatory subunit to the immunological synapse. J Immunol (2008) 181:1969-77. doi:10.4049/jimmunol.181.3.1969

21. Batista FD, Iber D, Neuberger MS. B cells acquire antigen from target cells after synapse formation. Nature (2001) 411:489-94. doi:10.1038/35078099

22. Fleire SJ, Goldman JP, Carrasco YR, Weber M, Bray D, Batista FD. B cell ligand discrimination through a spreading and contraction response. Science (2006) 312:738-41. doi:10.1126/science.1123940

23. Natkanski E, Lee WY, Mistry B, Casal A, Molloy JE, Tolar P. B cells use mechanical energy to discriminate antigen affinities. Science (2013) 340:1587-90. doi:10.1126/science.1237572

24. Nowosad CR, Spillane KM, Tolar P. Germinal center B cells recognize antigen through a specialized immune synapse architecture. Nat Immunol (2016) 17:870-7. doi:10.1038/ni.3458

25. Allen CD, Okada T, Tang HL, Cyster JG. Imaging of germinal center selection events during affinity maturation. Science (2007) 315:528-31. doi:10.1126/ science. 1136736

26. Yu D, Cook MC, Shin DM, Silva DG, Marshall J, Toellner KM, et al. Axon growth and guidance genes identify T-dependent germinal centre B cells. Immunol Cell Biol (2008) 86:3-14. doi:10.1038/sj.icb.7100123

27. Spillane KM, Tolar P. B cell antigen extraction is regulated by physical properties of antigen-presenting cells. J Cell Biol (2017) 216:217-30. doi: $10.1083 /$ jcb. 201607064

28. Koopman G, Keehnen RM, Lindhout E, Newman W, Shimizu Y, van Seventer GA, et al. Adhesion through the LFA-1 (CD11a/CD18)-ICAM-1 (CD54) and the VLA-4 (CD49d)-VCAM-1 (CD106) pathways prevents apoptosis of germinal center B cells. J Immunol (1994) 152:3760-7.

29. Victoratos P, Lagnel J, Tzima S, Alimzhanov MB, Rajewsky K, Pasparakis M, et al. FDC-specific functions of p55TNFR and IKK2 in the development of FDC networks and of antibody responses. Immunity (2006) 24:65-77. doi:10.1016/j.immuni.2005.11.013

30. El Shikh ME, El Sayed R, Szakal AK, Tew JG. Follicular dendritic cell (FDC)-FcgammaRIIB engagement via immune complexes induces the activated FDC phenotype associated with secondary follicle development. Eur J Immunol (2006) 36:2715-24. doi:10.1002/eji.200636122

31. Lindhout E, Mevissen ML, Kwekkeboom J, Tager JM, de Groot C. Direct evidence that human follicular dendritic cells (FDC) rescue germinal centre B cells from death by apoptosis. Clin Exp Immunol (1993) 91:330-6. doi:10.1111/j.1365-2249.1993.tb05904.x
32. Wang X, Cho B, Suzuki K, Xu Y, Green JA, An J, et al. Follicular dendritic cells help establish follicle identity and promote B cell retention in germinal centers. J Exp Med (2011) 208:2497-510. doi:10.1084/jem.20111449

33. Randall KL, Lambe T, Johnson AL, Treanor B, Kucharska E, Domaschenz H, et al. Dock8 mutations cripple B cell immunological synapses, germinal centers and long-lived antibody production. Nat Immunol (2009) 10:1283-91. doi:10.1038/ni.1820

34. Wang X, Rodda LB, Bannard O, Cyster JG. Integrin-mediated interactions between B cells and follicular dendritic cells influence germinal center B cell fitness. J Immunol (2014) 192:4601-9. doi:10.4049/jimmunol.1400090

35. Rahman ZS, Rao SP, Kalled SL, Manser T. Normal induction but attenuated progression of germinal center responses in BAFF and BAFF-R signalingdeficient mice. J Exp Med (2003) 198:1157-69. doi:10.1084/jem.20030495

36. Shulga-Morskaya S, Dobles M, Walsh ME, Ng LG, MacKay F, Rao SP, et al. B cell-activating factor belonging to the TNF family acts through separate receptors to support $\mathrm{B}$ cell survival and $\mathrm{T}$ cell-independent antibody formation. J Immunol (2004) 173:2331-41. doi:10.4049/jimmunol.173. 4.2331

37. Vora KA, Wang LC, Rao SP, Liu ZY, Majeau GR, Cutler AH, et al. Cutting edge: germinal centers formed in the absence of B cell-activating factor belonging to the TNF family exhibit impaired maturation and function. J Immunol (2003) 171:547-51. doi:10.4049/jimmunol.171.2.547

38. von Bulow GU, van Deursen JM, Bram RJ. Regulation of the T-independent humoral response by TACI. Immunity (2001) 14:573-82. doi:10.1016/S10747613(01)00130-3

39. Xu S, Lam KP. B-cell maturation protein, which binds the tumor necrosis factor family members BAFF and APRIL, is dispensable for humoral immune responses. Mol Cell Biol (2001) 21:4067-74. doi:10.1128/MCB.21.12.40674074.2001

40. Gardam S, Brink R. Non-canonical NF-kappaB signaling initiated by BAFF influences B cell biology at multiple junctures. Front Immunol (2014) 4:509. doi:10.3389/fimmu.2013.00509

41. Husson H, Lugli SM, Ghia P, Cardoso A, Roth A, Brohmi K, et al. Functional effects of TNF and lymphotoxin alpha1beta2 on FDC-like cells. Cell Immunol (2000) 203:134-43. doi:10.1006/cimm.2000.1688

42. Li L, Zhang X, Kovacic S, Long AJ, Bourque K, Wood CR, et al. Identification of a human follicular dendritic cell molecule that stimulates germinal center B cell growth. J Exp Med (2000) 191:1077-84. doi:10.1084/jem.191.6.1077

43. Zhang X, Li L, Jung J, Xiang S, Hollmann C, Choi YS. The distinct roles of $\mathrm{T}$ cell-derived cytokines and a novel follicular dendritic cell-signaling molecule 8D6 in germinal center-B cell differentiation. J Immunol (2001) 167: 49-56. doi:10.4049/jimmunol.167.1.49

44. Gil M, Park SJ, Chung YS, Park CS. Interleukin-15 enhances proliferation and chemokine secretion of human follicular dendritic cells. Immunology (2010) 130:536-44. doi:10.1111/j.1365-2567.2010.03252.x

45. Park CS, Yoon SO, Armitage RJ, Choi YS. Follicular dendritic cells produce IL-15 that enhances germinal center B cell proliferation in membrane-bound form. J Immunol (2004) 173:6676-83. doi:10.4049/jimmunol.173.11.6676

46. Kopf M, Herren S, Wiles MV, Pepys MB, Kosco-Vilbois MH. Interleukin 6 influences germinal center development and antibody production via a contribution of C3 complement component. J Exp Med (1998) 188:1895-906. doi:10.1084/jem.188.10.1895

47. Harker JA, Lewis GM, Mack L, Zuniga EI. Late interleukin-6 escalates $\mathrm{T}$ follicular helper cell responses and controls a chronic viral infection. Science (2011) 334:825-9. doi:10.1126/science.1208421

48. Nurieva RI, Chung Y, Martinez GJ, Yang XO, Tanaka S, Matskevitch TD, et al. Bcl6 mediates the development of T follicular helper cells. Science (2009) 325:1001-5. doi:10.1126/science.1176676

49. Boles KS, Vermi W, Facchetti F, Fuchs A, Wilson TJ, Diacovo TG, et al. A novel molecular interaction for the adhesion of follicular CD4 T cells to follicular DC. Eur J Immunol (2009) 39:695-703. doi:10.1002/eji.200839116

50. Locci M, Havenar-Daughton C, Landais E, Wu J, Kroenke MA, Arlehamn CL, et al. Human circulating PD-1+CXCR3-CXCR5+ memory Tfh cells are highly functional and correlate with broadly neutralizing HIV antibody responses. Immunity (2013) 39:758-69. doi:10.1016/j.immuni.2013.08.031

51. Godefroy E, Zhong H, Pham P, Friedman D, Yazdanbakhsh K. TIGITpositive circulating follicular helper T cells display robust B-cell help functions: potential role in sickle cell alloimmunization. Haematologica (2015) 100:1415-25. doi:10.3324/haematol.2015.132738 
52. Yu X, Harden K, Gonzalez LC, Francesco M, Chiang E, Irving B, et al. The surface protein TIGIT suppresses $\mathrm{T}$ cell activation by promoting the generation of mature immunoregulatory dendritic cells. Nat Immunol (2009) 10:48-57. doi:10.1038/ni.1674

53. Evans R, Patzak I, Svensson L, De Filippo K, Jones K, McDowall A, et al. Integrins in immunity. J Cell Sci (2009) 122:215-25. doi:10.1242/jcs.019117

54. Brunmark A, O'Rourke AM. Augmentation of mature CD4+ T cell responses to isolated antigenic class II proteins by fibronectin and intercellular adhesion molecule-1. J Immunol (1997) 159:1676-85.

55. Wulfing C, Sjaastad MD, Davis MM. Visualizing the dynamics of T cell activation: intracellular adhesion molecule 1 migrates rapidly to the $\mathrm{T}$ cell/B cell interface and acts to sustain calcium levels. Proc Natl Acad Sci U S A (1998) 95:6302-7. doi:10.1073/pnas.95.11.6302

56. Meli AP, Fontes G, Avery DT, Leddon SA, Tam M, Elliot M, et al. The integrin LFA-1 controls T follicular helper cell generation and maintenance. Immunity (2016) 45:831-46. doi:10.1016/j.immuni.2016.09.018

57. Zaretsky I, Atrakchi O, Mazor RD, Stoler-Barak L, Biram A, Feigelson SW, et al. ICAMs support B cell interactions with T follicular helper cells and promote clonal selection. J Exp Med (2017) 214:3435-48. doi:10.1084/ jem.20171129

58. Liu Y, Blanchfield L, Ma VP, Andargachew R, Galior K, Liu Z, et al. DNAbased nanoparticle tension sensors reveal that T-cell receptors transmit defined $\mathrm{pN}$ forces to their antigens for enhanced fidelity. Proc Natl Acad Sci U S A (2016) 113:5610-5. doi:10.1073/pnas.1600163113

59. Han S, Hathcock K, Zheng B, Kepler TB, Hodes R, Kelsoe G. Cellular interaction in germinal centers. Roles of CD40 ligand and B7-2 in established germinal centers. J Immunol (1995) 155:556-67.

60. Liu YJ, Joshua DE, Williams GT, Smith CA, Gordon J, MacLennan IC. Mechanism of antigen-driven selection in germinal centres. Nature (1989) 342:929-31. doi:10.1038/342929a0

61. Liu D, Xu H, Shih C, Wan Z, Ma X, Ma W, et al. T-B-cell entanglement and ICOSL-driven feed-forward regulation of germinal centre reaction. Nature (2015) 517:214-8. doi:10.1038/nature13803

62. Casamayor-Palleja M, Khan M, MacLennan IC. A subset of CD4+ memory $\mathrm{T}$ cells contains preformed CD40 ligand that is rapidly but transiently expressed on their surface after activation through the $\mathrm{T}$ cell receptor complex. J Exp Med (1995) 181:1293-301. doi:10.1084/jem.181.4.1293

63. Gardell JL, Parker DC. Despite disorganized synapse structure, Th2 cells maintain directional delivery of CD40L to antigen-presenting B cells. PLoS One (2017) 12:e0186573. doi:10.1371/journal.pone.0186573

64. Thauland TJ, Koguchi Y, Wetzel SA, Dustin ML, Parker DC. Th1 and Th2 cells form morphologically distinct immunological synapses. J Immunol (2008) 181:393-9. doi:10.4049/jimmunol.181.1.393

65. Papa I, Saliba D, Ponzoni M, Bustamante S, Canete PF, Gonzalez-Figueroa P, et al. TFH-derived dopamine accelerates productive synapses in germinal centres. Nature (2017) 547:318-23. doi:10.1038/nature23013

66. Cannons JL, Qi H, Lu KT, Dutta M, Gomez-Rodriguez J, Cheng J, et al. Optimal germinal center responses require a multistage $\mathrm{T}$ cell:B cell adhesion process involving integrins, SLAM-associated protein, and CD84. Immunity (2010) 32:253-65. doi:10.1016/j.immuni.2010.01.010

67. Cannons JL, Tangye SG, Schwartzberg PL. SLAM family receptors and SAP adaptors in immunity. Annu Rev Immunol (2011) 29:665-705. doi:10.1146/ annurev-immunol-030409-101302

68. Chtanova T, Tangye SG, Newton R, Frank N, Hodge MR, Rolph MS, et al. $\mathrm{T}$ follicular helper cells express a distinctive transcriptional profile, reflecting their role as non-Th1/Th2 effector cells that provide help for B cells. JImmunol (2004) 173:68-78. doi:10.4049/jimmunol.173.1.68

69. Ma CS, Suryani S, Avery DT, Chan A, Nanan R, Santner-Nanan B, et al. Early commitment of naive human $\mathrm{CD} 4(+) \mathrm{T}$ cells to the $\mathrm{T}$ follicular helper (T(FH)) cell lineage is induced by IL-12. Immunol Cell Biol (2009) 87: 590-600. doi:10.1038/icb.2009.64

70. QiH, Cannons JL, Klauschen F, Schwartzberg PL, Germain RN. SAP-controlled T-B cell interactions underlie germinal centre formation. Nature (2008) 455:764-9. doi:10.1038/nature07345

71. Schwartzberg PL, Mueller KL, Qi H, Cannons JL. SLAM receptors and SAP influence lymphocyte interactions, development and function. Nat Rev Immunol (2009) 9:39-46. doi:10.1038/nri2456

72. Chevalier N, Macia L, Tan JK, Mason LJ, Robert R, Thorburn AN, et al. The role of follicular helper $\mathrm{T}$ cell molecules and environmental influences in autoantibody production and progression to inflammatory arthritis in mice. Arthritis Rheumatol (2016) 68:1026-38. doi:10.1002/art.39481

73. Kim J, Kim YM, Jeoung DI, Choe J. Human follicular dendritic cells promote the APC capability of B cells by enhancing CD86 expression levels. Cell Immunol (2012) 273:109-14. doi:10.1016/j.cellimm.2012.01.003

74. Attridge K, Kenefeck R, Wardzinski L, Qureshi OS, Wang CJ, Manzotti C, et al. IL-21 promotes CD4 T cell responses by phosphatidylinositol 3-kinasedependent upregulation of CD86 on B cells. J Immunol (2014) 192:2195-201 doi:10.4049/jimmunol.1302082

75. Wang CJ, Heuts F, Ovcinnikovs V, Wardzinski L, Bowers C, Schmidt EM, et al. CTLA-4 controls follicular helper T-cell differentiation by regulating the strength of CD28 engagement. Proc Natl Acad Sci U S A (2015) 112: 524-9. doi:10.1073/pnas.1414576112

76. Pasterkamp RJ. Getting neural circuits into shape with semaphorins. Nat Rev Neurosci (2012) 13:605-18. doi:10.1038/nrn3302

77. Tamagnone L, Artigiani S, Chen H, He Z, Ming GI, Song H, et al. Plexins are a large family of receptors for transmembrane, secreted, and GPI-anchored semaphorins in vertebrates. Cell (1999) 99:71-80. doi:10.1016/S00928674(00)80063-X

78. Yan H, Wu L, Shih C, Hou S, Shi J, Mao T, et al. Plexin B2 and semaphorin 4C guide $\mathrm{T}$ cell recruitment and function in the germinal center. Cell Rep (2017) 19:995-1007. doi:10.1016/j.celrep.2017.04.022

79. Lu P, Shih C, Qi H. Ephrin B1-mediated repulsion and signaling control germinal center $\mathrm{T}$ cell territoriality and function. Science (2017) 356(6339):eaai9264. doi:10.1126/science.aai9264

80. Laidlaw BJ, Schmidt TH, Green JA, Allen CD, Okada T, Cyster JG. The Eph-related tyrosine kinase ligand Ephrin-B1 marks germinal center and memory precursor B cells. J Exp Med (2017) 214:639-49. doi:10.1084/jem. 20161461

81. Ostroumova OS, Schagina LV, Mosevitsky MI, Zakharov VV. Ion channel activity of brain abundant protein BASP1 in planar lipid bilayers. FEBS J (2011) 278:461-9. doi:10.1111/j.1742-4658.2010.07967.x

82. Frey D, Laux T, Xu L, Schneider C, Caroni P. Shared and unique roles of CAP23 and GAP43 in actin regulation, neurite outgrowth, and anatomical plasticity. J Cell Biol (2000) 149:1443-54. doi:10.1083/jcb.149.7.1443

83. Geiger B, Rosen D, Berke G. Spatial relationships of microtubule-organizing centers and the contact area of cytotoxic T lymphocytes and target cells. J Cell Biol (1982) 95:137-43. doi:10.1083/jcb.95.1.137

84. Kupfer A, Swain SL, Janeway CA Jr, Singer SJ. The specific direct interaction of helper T cells and antigen-presenting B cells. Proc Natl Acad Sci U S A (1986) 83:6080-3. doi:10.1073/pnas.83.16.6080

85. Poo WJ, Conrad L, Janeway CA Jr. Receptor-directed focusing of lymphokine release by helper T cells. Nature (1988) 332:378-80. doi:10.1038/ $332378 \mathrm{a} 0$

86. Choudhuri K, Llodra J, Roth EW, Tsai J, Gordo S, Wucherpfennig KW, et al. Polarized release of T-cell-receptor-enriched microvesicles at the immunological synapse. Nature (2014) 507:118-23. doi:10.1038/nature12951

87. Mittelbrunn M, Gutierrez-Vazquez C, Villarroya-Beltri C, Gonzalez S, Sanchez-Cabo F, Gonzalez MA, et al. Unidirectional transfer of microRNA-loaded exosomes from T cells to antigen-presenting cells. Nat Commun (2011) 2:282. doi:10.1038/ncomms1285

88. Huang JF, Yang Y, Sepulveda H, Shi W, Hwang I, Peterson PA, et al. TCRmediated internalization of peptide-MHC complexes acquired by $\mathrm{T}$ cells Science (1999) 286:952-4. doi:10.1126/science.286.5441.952

89. Wetzel SA, McKeithan TW, Parker DC. Peptide-specific intercellular transfer of MHC class II to CD4+ T cells directly from the immunological synapse upon cellular dissociation. J Immunol (2005) 174:80-9. doi:10.4049/ jimmunol.174.1.80

90. Huse M, Lillemeier BF, Kuhns MS, Chen DS, Davis MM. T cells use two directionally distinct pathways for cytokine secretion. Nat Immunol (2006) 7:247-55. doi:10.1038/ni1304

91. Reinhardt RL, Liang HE, Locksley RM. Cytokine-secreting follicular T cells shape the antibody repertoire. Nat Immunol (2009) 10:385-93. doi:10.1038/ ni. 1715

92. Pasqual G, Chudnovskiy A, Tas JMJ, Agudelo M, Schweitzer LD, Cui A, et al. Monitoring $\mathrm{T}$ cell-dendritic cell interactions in vivo by intercellular enzymatic labelling. Nature (2018) 553:496-500. doi:10.1038/nature25442

93. Kandel ER, Schwartz JH, Jessell TM, Siegelbaum SA, Hudspeth AJ. Principles of Neural Science. 5th ed. US: McGraw-Hill (2013). 
94. Rubi B, Maechler P. Minireview: new roles for peripheral dopamine on metabolic control and tumor growth: let's seek the balance. Endocrinology (2010) 151:5570-81. doi:10.1210/en.2010-0745

95. Sorriento D, Santulli G, Del Giudice C, Anastasio A, Trimarco B, Iaccarino G. Endothelial cells are able to synthesize and release catecholamines both in vitro and in vivo. Hypertension (2012) 60:129-36. doi:10.1161/ HYPERTENSIONAHA.111.189605

96. Bergquist J, Josefsson E, Tarkowski A, Ekman R, Ewing A. Measurements of catecholamine-mediated apoptosis of immunocompetent cells by capillary electrophoresis. Electrophoresis (1997) 18:1760-6. doi:10.1002/elps. 1150181009

97. Bergquist J, Silberring J. Identification of catecholamines in the immune system by electrospray ionization mass spectrometry. Rapid Commun Mass Spectrom (1998) 12:683-8. doi:10.1002/(SICI)1097-0231(19980615) $12: 11<683:: A I D-R C M 218>3.0 . C O ; 2-\mathrm{N}$

98. Bergquist J, Tarkowski A, Ekman R, Ewing A. Discovery of endogenous catecholamines in lymphocytes and evidence for catecholamine regulation of lymphocyte function via an autocrine loop. Proc Natl Acad Sci U S A (1994) 91:12912-6. doi:10.1073/pnas.91.26.12912

99. Cosentino M, Fietta AM, Ferrari M, Rasini E, Bombelli R, Carcano E, et al. Human CD4+CD25+ regulatory T cells selectively express tyrosine hydroxylase and contain endogenous catecholamines subserving an autocrine/ paracrine inhibitory functional loop. Blood (2007) 109:632-42. doi:10.1182/ blood-2006-01-028423

100. Ferrari M, Cosentino M, Marino F, Bombelli R, Rasini E, Lecchini S, et al. Dopaminergic D1-like receptor-dependent inhibition of tyrosine hydroxylase mRNA expression and catecholamine production in human lymphocytes. Biochem Pharmacol (2004) 67:865-73. doi:10.1016/j.bcp.2003.10.004

101. Flierl MA, Rittirsch D, Nadeau BA, Chen AJ, Sarma JV, Zetoune FS, et al. Phagocyte-derived catecholamines enhance acute inflammatory injury. Nature (2007) 449:721-5. doi:10.1038/nature06185

102. Flierl MA, Rittirsch D, Nadeau BA, Sarma JV, Day DE, Lentsch AB, et al. Upregulation of phagocyte-derived catecholamines augments the acute inflammatory response. PLoS One (2009) 4:e4414. doi:10.1371/journal. pone. 0004414

103. Josefsson E, Bergquist J, Ekman R, Tarkowski A. Catecholamines are synthesized by mouse lymphocytes and regulate function of these cells by induction of apoptosis. Immunology (1996) 88:140-6. doi:10.1046/j.1365-2567.1996. d01-653.x

104. Musso NR, Brenci S, Indiveri F, Lotti G. L-tyrosine and nicotine induce synthesis of L-Dopa and norepinephrine in human lymphocytes. J Neuroimmunol (1997) 74:117-20. doi:10.1016/S0165-5728(96)00212-3

105. Musso NR, Brenci S, Setti M, Indiveri F, Lotti G. Catecholamine content and in vitro catecholamine synthesis in peripheral human lymphocytes. J Clin Endocrinol Metab (1996) 81:3553-7. doi:10.1210/jcem.81.10.8855800

106. Nakano K, Higashi T, Takagi R, Hashimoto K, Tanaka Y, Matsushita S. Dopamine released by dendritic cells polarizes Th2 differentiation. Int Immunol (2009) 21:645-54. doi:10.1093/intimm/dxp033

107. Tsao CW, Lin YS, Cheng JT. Inhibition of immune cell proliferation with haloperidol and relationship of tyrosine hydroxylase expression to immune cell growth. Life Sci (1998) 62:335-44. doi:10.1016/S0024-3205(98)00170-2

108. Griffiths GM, Isaaz S. Granzymes A and B are targeted to the lytic granules of lymphocytes by the mannose-6-phosphate receptor. J Cell Biol (1993) 120:885-96. doi:10.1083/jcb.120.4.885

109. Shresta S, Pham CT, Thomas DA, Graubert TA, Ley TJ. How do cytotoxic lymphocytes kill their targets? Curr Opin Immunol (1998) 10:581-7. doi:10.1016/S0952-7915(98)80227-6

110. Stinchcombe JC, Griffiths GM. Secretory mechanisms in cell-mediated cytotoxicity. Annu Rev Cell Dev Biol (2007) 23:495-517. doi:10.1146/annurev. cellbio.23.090506.123521

111. Brown DM. Cytolytic CD4 cells: direct mediators in infectious disease and malignancy. Cell Immunol (2010) 262:89-95. doi:10.1016/j.cellimm. 2010.02 .008
112. Brown DM, Lampe AT, Workman AM. The differentiation and protective function of cytolytic CD4 T cells in influenza infection. Front Immunol (2016) 7:93. doi:10.3389/fimmu.2016.00093

113. Cheroutre H, Husain MM. CD4 CTL: living up to the challenge. Semin Immunol (2013) 25:273-81. doi:10.1016/j.smim.2013.10.022

114. Soghoian DZ, Streeck H. Cytolytic CD4(+) T cells in viral immunity. Expert Rev Vaccines (2010) 9:1453-63. doi:10.1586/erv.10.132

115. Swain SL, McKinstry KK, Strutt TM. Expanding roles for CD4(+) T cells in immunity to viruses. Nat Rev Immunol (2012) 12:136-48. doi:10.1038/ nri3152

116. Takeuchi A, Saito T. CD4 CTL, a cytotoxic subset of CD4(+) T cells, their differentiation and function. Front Immunol (2017) 8:194. doi:10.3389/ fimmu.2017.00194

117. Quezada SA, Simpson TR, Peggs KS, Merghoub T, Vider J, Fan X, et al. Tumor-reactive CD4(+) T cells develop cytotoxic activity and eradicate large established melanoma after transfer into lymphopenic hosts. J Exp Med (2010) 207:637-50. doi:10.1084/jem.20091918

118. Xie Y, Akpinarli A, Maris C, Hipkiss EL, Lane M, Kwon EK, et al. Naive tumor-specific CD4(+) T cells differentiated in vivo eradicate established melanoma. J Exp Med (2010) 207:651-67. doi:10.1084/jem.20091921

119. Peeters LM, Vanheusden M, Somers V, Van Wijmeersch B, Stinissen P, Broux B, et al. Cytotoxic CD4+ T cells drive multiple sclerosis progression. Front Immunol (2017) 8:1160. doi:10.3389/fimmu.2017.01160

120. Thewissen M, Somers V, Hellings N, Fraussen J, Damoiseaux J, Stinissen P. CD4+CD28null $\mathrm{T}$ cells in autoimmune disease: pathogenic features and decreased susceptibility to immunoregulation. J Immunol (2007) 179: 6514-23. doi:10.4049/jimmunol.179.10.6514

121. van de Berg PJ, van Leeuwen EM, ten Berge IJ, van Lier R. Cytotoxic human CD4(+) T cells. Curr Opin Immunol (2008) 20:339-43. doi:10.1016/j. coi.2008.03.007

122. Donnarumma T, Young GR, Merkenschlager J, Eksmond U, Bongard N, Nutt SL, et al. Opposing development of cytotoxic and follicular helper CD4 T cells controlled by the TCF-1-Bcl6 nexus. Cell Rep (2016) 17:1571-83. doi:10.1016/j.celrep.2016.10.013

123. Alshekaili J, Chand R, Lee CE, Corley S, Kwong K, Papa I, et al. STAT3 regulates cytotoxicity of human CD57+CD4+ T cells in blood and lymphoid follicles. Sci Rep (2018) 8:3529. doi:10.1038/s41598-018-21389-8

124. Nielsen CM, White MJ, Goodier MR, Riley EM. Functional significance of CD57 expression on human NK cells and relevance to disease. Front Immunol (2013) 4:422. doi:10.3389/fimmu.2013.00422

125. Shulman Z, Gitlin AD, Weinstein JS, Lainez B, Esplugues E, Flavell RA, et al. Dynamic signaling by $\mathrm{T}$ follicular helper cells during germinal center B cell selection. Science (2014) 345:1058-62. doi:10.1126/science.1257861

126. Liang L, Porter EM, Sha WC. Constitutive expression of the B7h ligand for inducible costimulator on naive B cells is extinguished after activation by distinct $\mathrm{B}$ cell receptor and interleukin 4 receptor-mediated pathways and can be rescued by CD40 signaling. J Exp Med (2002) 196:97-108. doi:10.1084/jem.20020298

127. Sacquin A, Gador M, Fazilleau N. The strength of BCR signaling shapes terminal development of follicular helper T cells in mice. Eur J Immunol (2017) 47:1295-304. doi:10.1002/eji.201746952

Conflict of Interest Statement: The authors declare that the research was conducted in the absence of any commercial or financial relationships that could be construed as a potential conflict of interest.

Copyright (C) 2018 Papa and Vinuesa. This is an open-access article distributed under the terms of the Creative Commons Attribution License (CC BY). The use, distribution or reproduction in other forums is permitted, provided the original author(s) and the copyright owner(s) are credited and that the original publication in this journal is cited, in accordance with accepted academic practice. No use, distribution or reproduction is permitted which does not comply with these terms. 